\title{
Reproduction in Wild Female Olive Baboons
}

\author{
BARBARA SMUTS ${ }^{1}$ AND NANCY NICOLSON ${ }^{2}$ \\ ${ }^{I}$ Department of Psychology and Department of Anthropology, University of Michigan, Ann \\ Arbor; ${ }^{2}$ Neuropsychology and Psychobiology, University of Limburg, Maastricht, The \\ Netherlands
}

The purpose of this paper is to evaluate several factors that influence female reproduction in a large troop of wild olive baboons (Papio cynocephalus anubis) based on 4 consecutive years of demographic data. Interbirth intervals were significantly shorter for females whose infants died before their next conception than for females whose infants survived. High-ranking mothers of surviving infants had significantly shorter birth intervals than comparable low-ranking mothers, independent of maternal age. This occurred mainly because the interval from resumption of cycling to conception was significantly shorter for high- vs. low-ranking females. Dominance rank did not influence sex ratio at birth, infant survival in the first 2 years, or adult female mortality. Age was also significantly related to interbirth intervals, with older females having shorter intervals. Primiparous females had consistently longer reproductive intervals than did multiparous females, but this difference reached statistical significance only for females whose infants died before the next conception. Primiparous females also experienced significantly higher infant mortality. Data on body size and estrous cycle length indicated no differences between high- and low-ranking females. Nutritional and stress-related mechanisms that may underlie the reproductive advantages of high rank are discussed.

Key words: interbirth interval, dominance, age, sex ratio, estrous cycles, body size, Papio cynocephalus

\section{INTRODUCTION}

Among the closely related macaques, baboons, and vervets, females form relatively stable linear dominance hierarchies [e.g., Kawai, 1965; Sade, 1967; Silk et al., 1981b; Hausfater et al., 1982; Seyfarth, 1980]. Females compete actively for high status [e.g., Walters, 1980; Datta, 1983], and when resources are very limited [Wrangham, 1981] or especially clumped [Whitten, 1983], dominant females gain access to them at the expense of subordinate females. Thus, female dominance relationships appear to reflect female-female competition over resources. Since resource acquisition has been linked to enhanced reproduction in a wide variety of mammals [Sadleier, 1969; Andersen et al., 1976], including primates [Mori, 1979;

Received for publication June 9, 1988; accepted November 8, 1989.

Address reprint requests to Barbara Smuts, Department of Psychology and Department of Anthropology, University of Michigan, Ann Arbor, MI 48109-1346. 
Strum \& Western, 1982; van Schaik \& van Noordwijk, 1985], we might expect high-ranking females to show greater reproductive success than low-ranking females.

Four main variables influence lifetime reproductive success in female mammals: 1) age at first reproduction, 2) fertility, 3) female mortality, and 4) offspringmortality. For each of these variables, some studies have reported an advantage for higher-ranking female macaques, baboons, and vervets, while other studies have found no such advantage [reviewed in Silk, 1987; Harcourt, 1987]. The bulk of the available data comes from captive or provisioned groups (e.g., provisioned rhesus [Drickamer, 1974]; provisioned Japanese macaques [Mori, 1979; Sugiyama \& Ohsawa, 1982; Gouzoules et al., 1982]; captive vervets [Fairbanks \& McGuire, 1984]; captive rhesus [Wilson et al., 1978]; captive bonnet macaques [Silk et al., 1981a]; captive talapoin monkeys [Keverne et al., 1984]). Information from wild primates indicates, in several cases, rank-related effects on aspects of reproduction (e.g., fewer cycles to conception in dominant female gelada baboons [Dunbar, 1980] and earlier menarche in high-ranking yellow baboons [Altmann et al., 1988]), but only rarely have rank effects been demonstrated for interbirth intervals or birth rate in species in which more than one female in a group breeds (toque macaques [Dittus, 1986]; vervet monkeys [Whitten, 1983]). Data from a long-term study of wild yellow baboons at Amboseli has revealed no relationship between female rank and fertility [Altmann, 1980; Altmann et al,, 1988]. In both the wild and captivity, factors other than rank influence female fertility, including age [Hrdy \& Hrdy, 1976; Dunbar, 1980; Strum \& Western, 1982; Dittus, 1975], sex of previous offspring [Simpson et al., 1981; Simpson \& Simpson, 1985], and group size [van Schaik, 1983; Silk, 1988].

In this paper we use 4 years of data from a large troop of wild savanna baboons (Papio cynocephalus anubis) to examine the effects of female dominance rank, female age, infant mortality, and sex of previous offspring on female fertility as measured by interbirth intervals. We then investigate how rank and age influence the different components of the interbirth interval and how these components relate to one another. Factors influencing female and infant mortality and the sex ratio at birth are also examined. We conclude by discussing our results in the context of an ongoing debate about whether lower fertility among subordinate female primates (when it occurs) is explained by inferior condition due to reduced access to food [e.g., Whitten, 1983; Harcourt, 1987] or is due to reduced probability of conception as a result of the stress of harassment by higher-ranking animals [e.g., Dunbar, 1980; Wasser, 1983; Wasser \& Starling, 1988].

\section{METHODS}

The analyses are based on demographic data collected on the Eburru Cliffs troop (EC), near Gilgil, Kenya, from August 1977 through August 1981 by Nicolson [1982], Smuts [1985], Johnson [1984, 1987], and Wilson (unpublished data). The study site and observation methods are described in detail elsewhere [Smuts, 1985]. EC included 115 animals when the study began and 135 at the end. Results are based on daily census records for the 56 females who conceived at least once during the study period. A few gaps in observation occurred when the troop could not be found. Data are included here only when the interval under consideration could be estimated to within 2 weeks. Of the 244 reproductive events (conception, birth, infant death, resumption of cycles) included in the analysis, the dates of $41 \%$ were known exactly, $35 \%$ were known to within 3 days, and the remainder were known to within 1 week. 


\section{Female Reproductive Parameters}

Savanna baboons display no or very slight reproductive seasonality [ Altmann, 1980; Nicolson, 1982]. The interbirth interval (labeled $I_{b b}$ here) includes three easily distinguished components: 1) the interval from birth of an infant until the female resumes estrous cycles (postpartum amenorrhea or $I_{b r}$ ); 2) the interval from resumption of cycling until the female conceives (duration of cycling or $I_{r c}$ ); and 3 ) the interval from conception until birth of the next infant (gestation). Female baboons display clear signs of ovarian hormone activity during each cycle, including menstruation, perineal swelling, and a rapid and obvious decrease in the size of the perineal swelling marking the onset of detumescence ("D-day") [Hausfater, 1975; Altmann et al., 1977, 1978, 1988]. Laboratory studies indicate that ovulation occurs shortly before D-day [Hendrickx \& Kraemer, 1969; Wildt et al., 1977; Shaikh et al., 1982]. Following Altmann et al. [1977], we assigned the date of conception to D-day of the female's last cycle before pregnancy. Resumption of estrous cycles was assigned to the first day of detectable swelling of the perineal area after birth or miscarriage.

To determine the length of the entire menstrual cycle, we measured from $\mathrm{D}$-day of one cycle to $\mathrm{D}$-day of the next cycle, because $\mathrm{D}$-day is the most unambiguous event in the cycle. Due to brief gaps in the census data, we sometimes had to estimate D-day. We included only those cycles in which the maximum error was 4 days or less ( $n=80$ cycles for 34 females). Cycles estimated in this way were very similar in average length ( 44.7 days) to those in which both D-days were known precisely (44.2 days, $n=43$ ). We also determined the lengths of the swelling phase (from first day of perineal swelling until D-day) and non-swelling phase (from D-day until first day of perineal swelling of the next cycle). We included only those swelling and non-swelling phases in which the error ranged from 0 to 2 days ( $n=47$ swelling phases and 31 non-swelling phases); for purposes of analysis, median values of swelling and non-swelling phases for each female were used.

\section{Female Dominance Rank}

Dominance ranks of adult and adolescent females were based on the outcomes of 3,779 dyadic agonistic interactions recorded by Smuts from August 1977 through December 1978 [Smuts, 1985]. During this period female dominance relationships were linear and completely stable. Between February and July 1979, the four highest-ranking females fell to the bottom of the hierarchy, and one other high-ranking female fell a few positions; dominance relationships among all other females remained unchanged [Johnson, 1987]. Data for the four females who fell to the bottom of the hierarchy were included in the analyses; we first segmented the data into two periods, before and after the rank changes, and then assigned ranks appropriately. We also report separately reproductive intervals for the four females who fell to the bottom of the hierarchy, since they provide a rare opportunity to compare reproductive performance for the same females when they were highand low-ranking.

\section{Female Body Size and Age Estimates}

In March 1979, most troop members were trapped. The baboons were tranquilized, examined, and released later the same day. Weights and body length measurements (from neck to base of tail) were obtained at this time. We use body mass index ([weight/(body length) $\left.{ }^{2}\right]$, as an indicator of female physical condition.

Females who had reached menarche were assigned to one of five age classes: 1 ) adolescent ( $n=18$; approximately $4-6$ years); 2 ) young/primiparous $(n=8$; approx- 
imately $6-8$ years); 3) younger middle-aged ( $n=12$; approximately $9-12$ years); 4 ) older middle-aged ( $n=14$; approximately $13-16$ years); 5 ) old ( $n=4$; approximately $17-20$ years); and 6 ) very old ( $n=1 ;>20$ years; this female died during the study). Because exact ages were not known, age estimates were based on patterns of dental eruption and wear for the 31 females who were trapped and on physical characteristics, such as pigmentation and texture of the perineal area, size and shape of the sexual swellings, and overall appearance, including body shape and condition of fur, as described by Strum and Western [1982]. (See Smuts [1985] for further details on age estimates.) Age class assignments for adolescent females and for young/primiparous females were reliable, since all of these females either underwent menarche during the study or were known to be nulliparous at the start of the study based on the button-like appearance of their nipples prior to giving birth. We consider age estimates for the other classes sufficiently reliable for the analyses conducted here because of a high degree of agreement between independent observers' age assessments [see Smuts, 1985]. The validity of using physical criteria to estimate female ages has been confirmed by subsequent observations of females of known ages (Strum, personal communication, and personal observation).

In this troop, as in other troops of macaques and savanna baboons, female age and dominance rank were independent $\left(\chi^{2}=.54, \mathrm{df}=3, \mathrm{n}=35, P=.91\right)$. Nevertheless, we used multivariate techniques to consider simultaneously effects of age and maternal rank (see below), because small sample sizes could lead to a confounding of their effects.

\section{Feeding and Feeding Supplants}

Feeding was defined as ingesting or processing (e.g., digging for corms) food. Data on rates of feeding supplants were gathered during 400 hours of 30 -minute focal samples on 25 pregnant or lactating females during the first 6 months of the study, when the troop fed mainly on corms. A supplant occurred whenever: 1) animal $\mathrm{A}$ approached within $2 \mathrm{~m}$ of animal $\mathrm{B}, 2) \mathrm{B}$ immediately abandoned her feeding site, and 3) A immediately fed at B's site.

\section{Behavior of Females Who Fell in Rank}

For a 3-month period, beginning about 3 months after the four highestranking females fell in rank (see above), 186 thirty-minute focal samples were conducted on the "fallen" females and on a comparison group of four other very low-ranking females matched to the fallen females by age class and reproductive status. These samples provided data on time spent feeding, approaches, avoidance of approaches, and rates of aggressive and submissive interactions. Proportion of time spent feeding was obtained from on-the-minute instantaneous samples of subject's activity during focal samples. An approach occurred whenever another adult female moved to within $2 \mathrm{~m}$ of the focal animal. An avoid occurred whenever the focal animal moved at least $1 \mathrm{~m}$ away from an approaching female. Aggression involved unilateral threats, chases, or attacks, and submission involved any unilateral submissive or fearful gestures, including repeated rapid glances at an approaching animal, fear-grin, crouching, gecking, or raising the tail.

\section{Data Analysis}

When the study terminated, several subjects had not yet completed intervals of interest, resulting in a significant percentage of open intervals for menarche to first conception $(25 \%), \mathrm{I}_{\mathrm{bb}}(58 \%), \mathrm{I}_{\mathrm{br}}(33 \%)$, and $\mathrm{I}_{\mathrm{rc}}(14 \%)$. Analysis based on only completed intervals would create a bias toward short intervals. The alternative 
approach adopted here uses survival analysis techniques that take into account the time during which each subject was at risk for events of interest (i.e., resumption of cycling; conception), whether or not the event actually occurred during the study.

Two types of survival analysis techniques were employed. Fully non-parametric life table methods were used to examine individually the relationship of a single variable to the length of a particular interval. The method of Kaplan \& Meier [1958] was used to estimate the survivorship function for each subgroup (e.g., high- vs. low-ranking females) for each variable (e.g., interbirth interval). The generalized Wilcoxon statistic was used to determine whether this function differed significantly between subgroups (BMDP-1L) [Dixon et al., 1985]. The Wilcoxon statistic is distributed like $\mathrm{a} \mathrm{Chi}^{2}$, and one rejects the null hypothesis for large values. We used these techniques to: 1 ) investigate effects of dominance rank on the interval from menarche to first conception and 2) investigate effects of death of the previous infant on $\mathrm{I}_{\mathrm{bb}}, \mathrm{I}_{\mathrm{br}}$, and $\mathrm{I}_{\mathrm{rc}}$. We also used life table analysis to see whether reproductive intervals for primiparous females (age class 1) differed from those of multiparous females (all other age classes), because, biologically, primipares represent a distinctive subset. The life table method was also used to generate mean values and standard errors for all samples that involved at least one open (censored) interval.

A second technique, the Cox proportional hazards regression model, was used to investigate the multivariate influence of several variables on reproductive intervals [Cox, 1972]. In this model, the independent variables are covariates (such as female rank or age). The model predicts the risk (or hazard) of an event (such as resumption of cycling or giving birth) that terminates the interval under consideration. The technique assumes that the log of the hazard rate may be modelled as log-linear functions of the covariates. In addition an underlying or baseline hazard function can be estimated. It has no specified form, and in this sense the model is also non-parametric. The analysis estimates a set of regression coefficients that relates the effect of each covariate to the hazard function (BMDP-2L) [Dixon et al., 1985]. The test statistic used here is the regression coefficient divided by the standard error of the sample, referred to below as RC/SE.

We used the Cox model for two analyses: 1) to investigate the multivariate influences of a) infant age at death, b) maternal parity, and c) maternal rank on reproductive intervals following the death of an infant and to 2) investigate the multivariate influence of a) maternal age class and b) maternal rank on reproductive intervals where the previous infant survived. Covariates were grouped as follows: infant age at death was a continuous variable, measured in days; maternal parity involved two groupings, primiparous vs. multiparous; maternal age was grouped by age class; and maternal rank involved two groupings, high-ranking (top half of the dominance hierarchy) vs. low-ranking (bottom half of the hierarchy). For each analysis, a significant effect indicates that the covariate influenced the hazard function when the effects of other covariates were taken into account; i.e., the results are analagous to those obtained by standard multiple regression techniques. All tests were two-tailed.

In the multivariate analysis of reproductive intervals where the previous infant survived, most females contributed only one data point but a few females contributed two, or occasionally three, data points. The results reported here treat different values for the same female as independent data points; when the analysis was repeated using only single values (the earliest in time) for females with more than one data point the results were very similar.

Effects of female age class and rank on body size were tested by using one-way 
TABLE I. Variables Influencing Reproductive Intervals Following Death of a Live-Born Infant*

\begin{tabular}{|c|c|c|c|c|c|c|}
\hline \multirow[b]{2}{*}{ Covariates } & \multicolumn{2}{|c|}{$\begin{array}{l}\text { A. Interval from } \\
\text { death of infant } \\
\text { to cycling }\end{array}$} & \multicolumn{2}{|c|}{$\begin{array}{l}\text { B. Duration } \\
\text { of cycling }\end{array}$} & \multicolumn{2}{|c|}{$\begin{array}{l}\text { C. Interval from } \\
\text { death of infant } \\
\text { to conception } \\
(A+B)\end{array}$} \\
\hline & $\mathrm{RC} / \mathrm{SE}$ & $P$ & $\mathrm{RC} / \mathrm{SE}$ & $P$ & $\mathrm{RC} / \mathrm{SE}$ & $P$ \\
\hline $\begin{array}{l}\text { Mother's parity (primiparous } \\
\text { versus multiparous females) }\end{array}$ & 1.61 & .11 & 2.06 & .04 & 2.01 & .04 \\
\hline Infant age at time of death & 1.86 & .06 & -2.52 & .01 & -1.85 & .06 \\
\hline $\begin{array}{l}\text { Mother's rank (high-vs. } \\
\text { low-ranking females) }\end{array}$ & -1.40 & .16 & 0.33 & .74 & 0.40 & .69 \\
\hline
\end{tabular}

* $\mathrm{RC} / \mathrm{SE}=$ regression coefficient/standard error derived from the Cox proportional hazards analysis (see text). The sign of RC/SE indicates the relationship between the covariate and the hazard function. A negative coefficient decreases the value of the hazard function and therefore indicates a longer interval as the value of the covariate increases. A positive coefficient has the reverse interpretation. For example, in column B, the RC/SE value of -2.52 for the covariate "age of infant at time of death" indicates that as infant age of death increased, the length of time the mother spent cycling also increased.

analysis of variance and t-tests, respectively. Standard non-parametric tests were employed in the remaining analyses by using the Systat statistical package; all tests were two-tailed unless otherwise indicated.

\section{RESULTS}

\section{Menarche to First Conception}

Wild female baboons reach menarche between 4 and 5 years of age [Altmann et al., 1988; Strum \& Western, 1982; Scott, 1984]. After menarche, females typically cycle for 1 to 2 years before conceiving for the first time. In our sample, age at menarche and at first reproduction was not known, and rank effects on these parameters could therefore not be assessed. The average interval from menarche to first conception was not significantly different for low-ranking ( $\bar{X}=604$ days, $\mathrm{SE}=77.8, \mathrm{n}=11$ ) vs. high-ranking $(\overline{\mathrm{X}}=563$ days, $\mathrm{SE}=51.2, \mathrm{n}=13$ ) females (Generalized Wilcoxon $=.43, \mathrm{df}=1, P=.51$ ).

\section{Factors Influencing Interbirth Intervals}

Death of previous infant. Females resumed cycling on average 30 days (range 10-98 days, $\mathrm{n}=17$ ) after miscarriage or death of an infant. This rapid resumption of cycling significantly reduced postpartum amenorrhea for females who lost infants compared to females whose previous infants survived (infant died, $\overline{\mathrm{X}}=210$ days, $\mathrm{SE}=38.8, \mathrm{n}=20$; infant survived, $\overline{\mathrm{X}}=407, \mathrm{SE}=18.5, \mathrm{n}=61$; Generalized Wilcoxon $=27.53, \mathrm{df}=1, P=.00$ ). Neither cycle duration (infant died, $\overline{\mathrm{X}}=148, \mathrm{SE}=22.3, \mathrm{n}=18$; infant survived, $\overline{\mathrm{X}}=170, \mathrm{SE}=21.0, \mathrm{n}=39$; Generalized Wilcoxon $=0.26 \mathrm{df}=1, P=.61$ ) nor the number of cycles to conception (infant died, $\overline{\mathrm{X}}=4.1$ cycles, $\mathrm{SE}=.57$; infant survived, $\overline{\mathrm{X}}=5.0$ cycles, $\mathrm{SE}=.60$; Mann-Whitney $\mathrm{U}$ test: $\mathrm{U}=98, \mathrm{n}_{1}=12, \mathrm{n}_{2}=20, P=.39$ ) were significantly reduced for females who had lost infants.

We investigated the influence of three covariates on reproductive intervals following death of an infant: maternal parity, age of infant at time of death, and maternal rank (Table I). Primiparous females took significantly longer to conceive $(\bar{X}=218$ days, $\mathrm{SE}=48.3, \mathrm{n}=4$ ) after infant loss than did multiparous females ( $\overline{\mathrm{X}}=147$ days, $\mathrm{SE}=22.6, \mathrm{n}=10$ ). This was due both to a longer interval from infant 
TABLE II. Interbirth Interval and Its Components (in Days) as a Function of Rank*

\begin{tabular}{|c|c|c|c|c|}
\hline & $\begin{array}{l}\text { All females } \\
(\mathrm{SE})(\mathrm{N})\end{array}$ & $\begin{array}{l}\text { High-ranking } \\
\text { females }(\mathrm{SE})(\mathrm{N})\end{array}$ & $\begin{array}{c}\text { Low-ranking } \\
\text { females }(\mathrm{SE})(\mathrm{N})\end{array}$ & $P$ \\
\hline Mean interbirth interval & $760(34.68)(23)$ & $696(37.61)(14)$ & $860(53.20)(9)$ & .00 \\
\hline $\begin{array}{l}\text { Mean duration postpartum } \\
\text { amenorrhea }\end{array}$ & $407(18.48)(61)$ & $379(24.29)(34)$ & $441(28.07)(27)$ & .09 \\
\hline Mean duration cycling & $170(21.01)(39)$ & $127(17.0)(21)$ & $217(37.52)$ & .05 \\
\hline Mean duration gestation & $180(0.98)(13)$ & $180(1.12)(9)$ & $181(2.43)(4)$ & .46 \\
\hline
\end{tabular}

*This table includes data only for females whose previous infants survived until the mother's next conception or, for censored intervals, until the end of the study. Sample sizes vary because accurate data on all intervals were not available for all females. As a result, values for the three components of the interbirth interval do not sum exactly to the values given for the interbirth interval. For the first three intervals, $P$ values are based on the Cox proportional hazards analysis (see text). For gestation, the $P$ value is based on a t-test.

death until resumption of cycling (primipares, $\bar{X}=59$ days, $\mathrm{SE}=14.9, \mathrm{n}=4$; multipares, $\overline{\mathrm{X}}=13$ days, $\mathrm{SE}=2.9, \mathrm{n}=10$ ) and a longer time spent cycling (primipares, $\overline{\mathrm{X}}=159$ days, $\mathrm{SE}=45.5, \mathrm{n}=4$; multipares, $\overline{\mathrm{X}}=134$ days, $\mathrm{SE}=22.0, \mathrm{n}=10$ ), although parity effects were significant only for the latter interval (Table I). Infant age at time of death had paradoxical effects. Mothers who lost older infants had shorter intervals from infant death until resumption of cycling (although the effect did not quite reach statistical significance; Table I), but these same mothers spent significantly more time cycling and thus took significantly longer to conceive again. Mother's rank had no significant effect on time until resumption of cycling, time spent cycling, or these two intervals combined.

Because death of the previous infant affected the interbirth interval, all of the analyses that follow include only females whose previous infants survived until their next conception.

Female rank and age. Female rank, age, and sex of previous infants were investigated as covariates influencing interbirth intervals. Female rank showed a significant relationship with the interbirth interval ( $\mathrm{RC} / \mathrm{SE}=-3.17, P=.00$ ). $\mathrm{I}_{\mathrm{bb}}$ for low-ranking females whose previous infants survived until the female's next conception ( $\overline{\mathrm{X}}=860$ days, $\mathrm{SE}=53.2, \mathrm{n}=9$ ) was almost 6 months longer than the comparable interval for high-ranking females $(\bar{X}=696$ days, $S E=37.6, n=14$ ) (Table II).

Age also had a significant effect on interbirth interval, with older females showing shorter intervals ( $\mathrm{RC} / \mathrm{SE}=2.23, P=.03$ ) (Table III). The interval from first to second birth (age class 2 ) tended to be longer $(\bar{X}=946$ days, $\mathrm{SE}=60.5, \mathrm{n}=2$ ) than subsequent interbirth intervals $(\overline{\mathrm{X}}=743$ days, $\mathrm{SE}=35.4, \mathrm{n}=21)$, but this difference was not significant (Generalized Wilcoxon $=.52, \mathrm{~d} f=1, P=.56$ ).

Sex of previous infant. The sex of the previous infant had no effect on the subsequent $\mathrm{I}_{\mathrm{bb}}$ (male infant, $\overline{\mathrm{X}}=750$ days, $\mathrm{SE}=53.3, \mathrm{n}=8$; female infant, $\overline{\mathrm{X}}=766$ days, $\mathrm{SE}=46.2, \mathrm{n}=15 ; \mathrm{RC} / \mathrm{SE}=-.98, P=.32$ ).

\section{Components of the Interbirth Interval}

Female rank and age were investigated as covariates influencing components of the interbirth interval.

Duration of postpartum amenorrhea. For low-ranking females $I_{b r}$ averaged 441 days $(\mathrm{SE}=28.1, \mathrm{n}=27), 2$ months longer than for high-ranking females $(\mathrm{X}=379$ days, $\mathrm{SE}=24.3, \mathrm{n}=34$ ) (Table II), but this difference was not significant ( $\mathrm{RC} / \mathrm{SE}=-1.70, P=.09$ ).

Age did not significantly influence the duration of postpartum amenorrhea 
TABLE III. Interbirth Interval, Duration of Postpartum Amenorrhea, and Duration of Cycling (in Days) as a Function of Age Class*

\begin{tabular}{|c|c|c|c|c|c|}
\hline & $\begin{array}{c}\text { Age } \\
\text { class } 2 \\
(\mathrm{SE})(\mathrm{N})\end{array}$ & $\begin{array}{c}\text { Age } \\
\text { class } 3 \\
(\mathrm{SE})(\mathrm{N})\end{array}$ & $\begin{array}{c}\text { Age } \\
\text { class } 4 \\
(\mathrm{SE})(\mathrm{N})\end{array}$ & $\begin{array}{c}\text { Age } \\
\text { class } 5 \\
(\mathrm{SE})(\mathrm{N})\end{array}$ & $P$ \\
\hline $\begin{array}{l}\text { Mean } \\
\text { interbirth } \\
\text { interval }\end{array}$ & $\begin{array}{c}946 \\
(60.50)(2)\end{array}$ & $\begin{array}{c}782 \\
(64.39)(5)\end{array}$ & $\begin{array}{c}742 \\
(43.54)(15)\end{array}$ & $\begin{array}{c}550 \\
(0)(1)\end{array}$ & .03 \\
\hline $\begin{array}{c}\text { Mean duration } \\
\text { postpartum } \\
\text { amenorrhea }\end{array}$ & $\begin{array}{c}465 \\
(62.38)(9)\end{array}$ & $\begin{array}{c}396 \\
(22.35)(21)\end{array}$ & $\begin{array}{c}419 \\
(27.53)(29)\end{array}$ & $\begin{array}{c}157 \\
(21)(2)\end{array}$ & .36 \\
\hline $\begin{array}{l}\text { Mean duration } \\
\text { cycling }\end{array}$ & $\begin{array}{c}251 \\
(91.63)(5)\end{array}$ & $\begin{array}{c}177 \\
(38.51)(11)\end{array}$ & $\begin{array}{c}142 \\
(24.62)(21)\end{array}$ & $\begin{array}{r}232 \\
(0)(1)\end{array}$ & 1.00 \\
\hline
\end{tabular}

*This table includes data only for females whose previous infants survived until the mother's next conception, or, for censored intervals, until the end of the study. $P$ values are based on the Cox proportional hazards analysis (see text).

(RC/SE $=.92, P=.36$ ) (Table III), and primiparous females did not take significantly longer to resume cycles $(\overline{\mathrm{X}}=465$ days, $\mathrm{SE}=62.4, \mathrm{n}=9$ ) than multiparous females $(\overline{\mathrm{X}}=401$ days, $\mathrm{SE}=19.3, \mathrm{n}=52)$ (Generalized Wilcoxon $=.52, \mathrm{df}=1$, $P=.47)$.

Duration of cycling. Low-ranking females cycled on average about 3 months longer $(\overline{\mathrm{X}}=217$ days, $\mathrm{SE}=37.5, \mathrm{n}=18)$ than did high-ranking females $(\overline{\mathrm{X}}=127$ days, $\mathrm{SE}=17.0, \mathrm{n}=21)$, and this difference was significant $(\mathrm{RC} / \mathrm{SE}=-1.97, P=.05)$ (Table II). Consistent with this result, high-ranking females tended to have fewer cycles to conception $(\bar{X}=4.0)$ than lower-ranking females $(\bar{X}=6.0)$ (Mann-Whitney $\mathrm{U}$ test, $\mathrm{U}=29, \mathrm{n}_{1}=10, \mathrm{n}_{2}=10, P=.11$ ). The swelling phase of the cycle was significantly longer for low-ranking females $(\bar{X}=26$ days, $S E=1.6)$ than for highranking females $\left(\bar{X}=22\right.$ days, $S E=0.7$ ) (Mann-Whitney $U$ test, $U=43, n_{1}=18$, $\mathrm{n}_{2}=9, P=.05$ ). However, the luteal phase showed an opposite, although non-significant, pattern (low-ranking females: 20 days, $\mathrm{SE}=1.6$; high-ranking females, 22 days, $\mathrm{SE}=6.7$; Mann-Whitney $\mathrm{U}$ test, $\mathrm{U}=32, \mathrm{n}_{1}=13, \mathrm{n}_{2}=5, P=.96$ ), and the median cycle length was exactly the same (42 days) for 19 high-ranking and 14 low-ranking females.

Female age had no significant effect on duration of cycling (Table III; RC/ $\mathrm{SE}=.00, P=1.00$ ), and, again, primiparous females did not cycle for significantly longer $(\overline{\mathrm{X}}=251$ days, $\mathrm{SE}=91.6, \mathrm{n}=5$ ) than multiparous females $(\overline{\mathrm{X}}=160$ days, $\mathrm{SE}=20.5, \mathrm{n}=34$ ) (Generalized Wilcoxon $=.34$, $\mathrm{df}=1, P=.56$ ). If one used completed intervals only, the duration of postpartum amenorrhea and the length of time a female spent cycling were not correlated (Spearman rank correlation, $\left.\mathrm{r}_{\mathrm{s}}=.17, \mathrm{n}=30, P>.05\right)$, indicating that these two important components of the interbirth interval were independent.

Gestation. For 13 cases, the date of conception and the date of birth were known precisely. Gestation averaged 180.15 days $(\mathrm{SE}=.98)$ and did not differ between high- and low-ranking females (Table II).

\section{Mortality}

Infants of primiparous females were significantly more likely to die during the first year of life than were infants of multiparous females (Table IV). By the end of the second year of life, however, infant mortality was similar for primiparous and multiparous females (Table IV). Rates of infant mortality during the first year and 
TABLE IV. Infant Mortality as a Function of Mother's Parity, Mother's Rank, and Infant Sex

\begin{tabular}{lcccc}
\hline & $\begin{array}{c}\text { Interval } \\
\text { (months) }\end{array}$ & $\begin{array}{l}\text { No. } \\
\text { alive }\end{array}$ & $\begin{array}{c}\text { No. } \\
\text { dead }\end{array}$ & $\begin{array}{c}\text { Fisher's } \\
\text { exact } \\
\text { probability }\end{array}$ \\
\hline $\begin{array}{l}\text { Mother's parity } \\
\text { Primiparous }\end{array}$ & $0-12$ & 3 & 4 & \\
Multiparous & & 36 & 7 & .03 \\
Primiparous & $0-24$ & 2 & 5 & .18 \\
Multiparous & & 19 & 15 & \\
Mother's rank & & & & .50 \\
High & $0-12$ & 20 & 5 & .44 \\
Low & & 19 & 6 & \\
High & $0-24$ & 12 & 10 & .27 \\
Low & & 9 & 10 & .14 \\
Infant sex & & & & \\
F & $0-12$ & 24 & 5 & \\
M & & 15 & 6 & \\
F & $0-24$ & 15 & 10 & \\
M & & 6 & 10 & \\
\hline
\end{tabular}

the first 2 years of life were not affected by the infant's sex or by the mother's rank (Table IV). Nor was there any evidence that offspring survival in the first 2 years was an interactive function of infant sex and maternal rank (proportion of infants surviving for high-ranking females: female infants, .62, male infants, .43; proportion surviving for low-ranking females: female infants, .60, male infants, .38).

Twelve adult females (i.e., females that had conceived at least once) died during the 4-year study period. Six of them were high-ranking and six were lowranking, indicating that female rank had no effect on probability of dying. The age distributions of high- and low-ranking females who died were also very similar. Since females spend approximately half of their adult years in postpartum amenorrhea caring for an infant, Altmann [1980; Altmann et al., 1988] suggested that half the females who die should be in this reproductive state if the probability of death is independent of reproductive condition. In EC, this expectation was upheld (Table V); the period of lactation did not increase maternal mortality risk.

\section{Sex Ratio at Birth}

Sex ratio at birth was not related to maternal rank (high-ranking females: male infants $=19$, female infants $=16$; low-ranking females, male infants $=12$, female infants $=23 ; \chi^{2}=2.84, \mathrm{df}=1, \mathrm{n}=70, P=.92$ ).

\section{Feeding Rates and Body Size}

During the first 6 months of the study, the baboons fed mainly on corms, the storage organ of a sedge grass, and competition for feeding sites was frequently observed. Lower-ranking females lost corm feeding sites to higher-ranking females, and rate of loss of feeding sites correlated significantly with rank 
TABLE V. Expected and Observed Probability of Death for Adult Females in Different Reproductive States*

\begin{tabular}{lccc} 
Reproductive & $\begin{array}{c}\text { Mean No. of } \\
\text { days spent in } \\
\text { each reproductive } \\
\text { state }\end{array}$ & $\begin{array}{c}\text { Expected probability } \\
\text { of death for a given } \\
\text { reproductive state }\end{array}$ & $\begin{array}{c}\text { Observed probability } \\
\text { of death for a given } \\
\text { reproductive state }\end{array}$ \\
\hline Postpartum amenorrhea & 319 & .490 & .454 \\
Cycling & 152 & .234 & .273 \\
Gestation & 180 & .277 & .273 \\
\hline
\end{tabular}

*Based on 11 deaths that occurred during the 4-year study. One female who died after appearing to undergo menopause was eliminated. Values for number of days in each reproductive state are based on the average duration of each reproductive state for all females, taking into account differences in duration of postpartum amenorrbea and cycling for females who suffered infant loss and those who did not and the relative numbers of females who did and did not suffer infant loss.

(Spearman rank correlation, $\mathrm{r}_{\mathrm{s}}=.81, \mathrm{n}=30, P<.01$ ) (Fig. 1a). The rate at which females supplanted other females and took over their corm feeding sites also correlated significantly with rank $\left(\mathrm{r}_{\mathrm{s}}=.62, \mathrm{n}=30, P<.05\right)$ (Fig. 1b). However, lowranking females did not differ significantly from high-ranking females in body length, body weight, or body mass index (Table VI). All three measures varied significantly as a function of age class (Table VI). The greatest increase in body length occurred between age classes 2 and 3, whereas body mass index declined during the same period, suggesting that females actually lost weight per unit body length during the transition from age class 2 to 3.

\section{Effects of Loss of High Rank}

The four females who fell to the bottom of the dominance hierarchy during the study period had longer interbirth intervals thereafter (3.4 months longer using median values) than females in the bottom half of the dominance hierarchy, indicating that loss of rank affected fertility. (Amenorrhea was $17 \%$ longer for fallen females and duration of cycling was $20 \%$ longer.) The mean proportion of time spent feeding did not differ between the fallen females and four other low-ranking females matched for age and reproductive condition (fallen females: $\bar{X}=.58$, $\mathrm{SE}=.05$; low-ranking females: $\overline{\mathrm{X}}=.66, \mathrm{SE}=.03$; Mann-Whitney $\mathrm{U}$ test, $\mathrm{U}=4$, $\mathrm{n}_{1}=4, \mathrm{n}_{2}=4, P=.25$ ). However, the fallen females tended to receive more approaches from higher-ranking females than did the low-ranking controls (mean number of approaches per hour: fallen females: $3.35, \mathrm{SE}=.28$; low-ranking females: $2.41, \mathrm{SE}=.33$; Mann-Whitney $\mathrm{U}$ test, $\mathrm{U}=2, \mathrm{n}_{1}=4, \mathrm{n}_{2}=4, P=.08$ ). The fallen females also avoided a significantly higher proportion of these approaches (fallen females: $\overline{\mathrm{X}}=.55, \mathrm{SE}=.03$; low-ranking females: $\overline{\mathrm{X}}=.32, \mathrm{SE}=.09$; MannWhitney $\mathrm{U}$ test, $\mathrm{U}=0, \mathrm{n}_{1}=4, \mathrm{n}_{2}=4, P=.02$ ). Rates of aggression received and submission shown, however, did not differ significantly between the two groups (mean rate of aggression received/hr: fallen females: $\overline{\mathrm{X}}=.25, \mathrm{SE}=.05$; low-ranking females: $\overline{\mathrm{X}}=.17, \mathrm{SE}=.04$; Mann-Whitney $\mathrm{U}$ test, $\mathrm{U}=4, \mathrm{n}_{1}=4, \mathrm{n}_{2}=4, P=.25$; mean rate of submission shown/hr: fallen females: $\overline{\mathrm{X}}=.21, \mathrm{SE}=.02$; low-ranking females: $\overline{\mathrm{X}}=.19, \mathrm{SE}=.09$; Mann-Whitney $\mathrm{U}$ test, $\mathrm{U}=4, \mathrm{n}_{1}=4, \mathrm{n}_{2}=4, P=.25$ ).

\section{DISCUSSION}

\section{Mechanisms Through Which Female Dominance Could Affect Fertility}

We report a strong, statistically significant relationship between female dominance and interbirth interval in wild olive baboons. High-ranking females had 

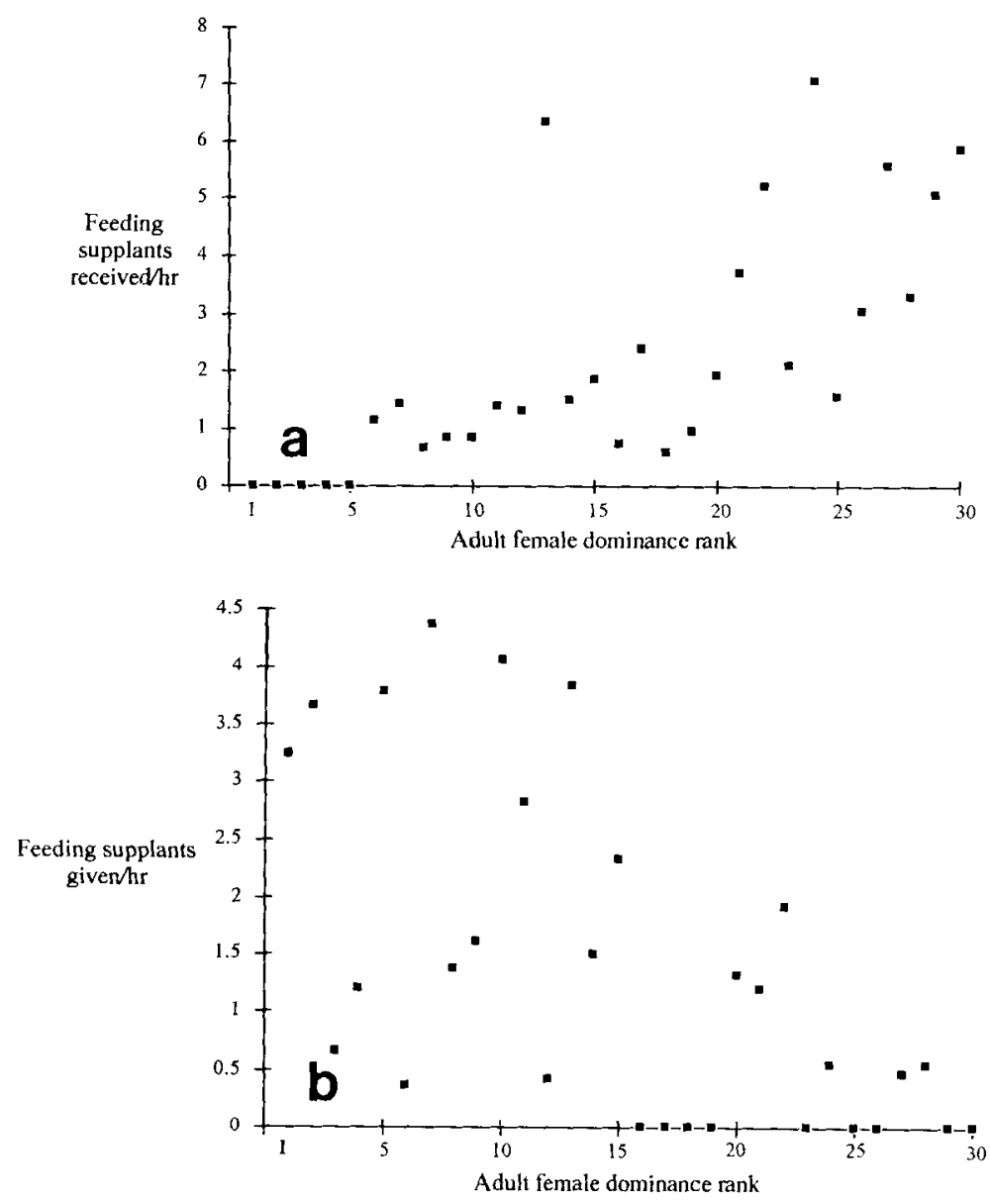

Fig. 1. a: Rate of feeding supplants received. Data shown represent rates of feeding supplants received per hour spent feeding on corms (total $=\mathbf{5 4}$ hours) by females as a function of dominance rank. Only supplants by other adult and adolescent (i.e., post-menarcheal) females are included. b: Rate of feeding supplants given. Data shown represent rates of feeding supplants given per hour spent feeding on corms (total $=54$ hours) by females as a function of dominance rank. Only supplants of other adult and adolescent females are included.

birth intervals that were almost 6 months (or 20\%) shorter, on average, than those of low-ranking females.

An association between female rank and fertility has been demonstrated in many but certainly not all studies of wild and captive primate groups [reviewed by Harcourt, 1987; Silk, 1987]. The conditions under which competitive ability is translated into higher reproductive success would be clarified if we could identify the underlying mechanisms. The link between rank and fertility could be mediated by differences among females in nutritional condition, stress due to harassment, or maternal behavior.

Nutrition. Nutritional factors have been shown to affect fertility in studies of humans, captive primates, and many other mammalian species, either directly, because poorly nourished females do not have adequate fat stores to resume cycling, or indirectly, because poor nutrition results in inadequate milk production [Loudun et al., 1983; Lunn, 1985], more frequent suckling by the current infant, 
TABLE VI. Female Body Size as a Function of Rank and Age Class*

\begin{tabular}{lccc}
\hline & $\begin{array}{c}\text { Mean body weight } \\
\mathrm{kg}(\mathrm{SE})(\mathrm{N})\end{array}$ & $\begin{array}{c}\text { Mean body length, } \\
\mathrm{cm}(\mathrm{SE})(\mathrm{N})\end{array}$ & $\begin{array}{c}\text { Mean body mass index } \\
\text { [weight/length }\end{array}$ \\
\hline $\begin{array}{l}\text { All females } \\
\text { Female rank }\end{array}$ & $12.71(.23)(31)$ & $43.70(.00)(29)$ & $66.87(1.40)(29)$ \\
$\quad$ High & $12.84(.32)(18)$ & $43(.01)(17)$ & $68.33(1.40)(17)$ \\
$\quad$ Low & $12.52(.35)(13)$ & $44(.01)(12)$ & $64.81(2.70)(12)$ \\
Female age class & & & \\
2 & $11.52(.22)(6)$ & $42(.01)(5)$ & $66.60(3.38)(5)$ \\
3 & $12.30(.37)(10)$ & $45(.01)(9)$ & $61.78(2.29)(9)$ \\
4 & $13.65(.29)(12)$ & $44(.00)(12)$ & $72.19(1.29)(12)$ \\
5 & $12.70(.95)(3)$ & $45(.01)(3)$ & $61.35(3.93)(3)$ \\
\hline
\end{tabular}

* Sample sizes vary because, for two females who were weighed, body length was not available. Analysis by rank: 1) weight: $\mathrm{t}(29)=.67, P=.51 ; 2)$ length: $\mathrm{t}(27)=.91, P=.37 ; 3)$ mass: $\mathrm{t}(27)=1.25, P=.22$. Analysis by age: 1) weight: $\mathrm{F}(3,29)=6.28, P=.00 ; 2)$ length: $\mathrm{F}(3,27)=3.29, P=.04,3)$ mass: $\mathrm{F}(3,27)=6.03, P=.00$. Pregnant females $(\mathrm{N}=5)$ weighed significantly more than lactating females, but the age-specific values for body weight and body mass index changed little when pregnant females were excluded, and age effects remained significant.

and subsequent inhibition of cycling and ovulation [reviewed by Lee, 1987]. In primates, ecological variables such as habitat quality, interspecific competition, population density, provisioning, and seasonal differences in rainfall or food availability have been used to explain population or intergroup differences in reproductive rate and changes in reproductive parameters over time [Strum \& Western, 1982; Whitten, 1983; van Schaik, 1983; Silk, 1986; Cheney et al., 1988]. Better nutrition is also an explanation for the higher reproductive rates of captive compared to wild primates [Lee, 1987].

While there is no doubt that nutrition affects reproductive performance, this mechanism may not be sufficient to explain individual differences in reproduction within a group. Only when the nature and distribution of food resources are such that high-ranking females can achieve higher rates of intake than low-ranking females will nutritional mechanisms play a role. This situation is most likely to occur when individuals can monopolize patches of high-quality food [Harcourt, 1987]. Whitten [1983], for example, reports higher feeding rates, larger body size, and increased fertility in high-ranking vervet monkeys living in a home range with a clumped food distribution. No such relationships were found in a nearby troop whose food showed a less clumped distribution. Similarly, in wild Japanese macaques undergoing minimal artificial feeding, high-ranking females weighed more than low-ranking females and had higher fertility [Mori, 1979], but in captive vervets [Fairbanks \& McGuire, 1984] and provisioned Japanese macaques [Sugiyama \& Ohsawa, 1982], no differences in the weights of high- vs. low-ranking females were found, although high-ranking females did indeed have higher fertility. In the latter study, the infants of high-ranking females had higher growth rates, suggesting that their mothers may have translated better nutrition into higher milk production.

In most savannah baboon habitats, however, food is widely and fairly evenly dispersed, which means that high-ranking females are likely to have little feeding advantage over low-ranking females. Indeed, little evidence for rank-related differences in feeding efficiency has been reported for wild baboons [Post et al., 1980; Altmann, 1980; Post, 1981; but see Rasmussen, 1985]. In our study, although female rank clearly affected aspects of feeding behavior under some conditions 
(e.g., more frequent displacement of lower-ranking females from seasonal cormdigging sites), it is not clear whether rank-related differences in food intake were large or persistent enough throughout the study period to account for the fertility patterns we have described. However, the significant positive relationship between female age and fertility in EC troop may indicate a nutritional influence on fertility, since body weight also increased with age (until old age).

Although studies of wild baboons provide some evidence that differences in food availability can influence the interval from resumption of cycling to conception [Berkovitch, 1985, 1987] and even gestation length [Silk, 1986], it seems reasonable to expect that nutritional factors will have the greatest effect on the duration of lactational amenorrhea, due to the high energetic costs of milk production [Lee, 1987]. Our data, however, indicate the strongest effect of female rank on the duration of the cycling interval, which suggests that stress may have played a role.

Stress. Social stress has been proposed as an alternative explanation for dominance effects on female reproduction, most often for primate groups in which either rates of aggression are high or food competition is thought to be low (for example, captive groups [Rowell, 1970; Silk et al., 1981a; Keverne et al., 1984]) or for species that feed on relatively low-quality, evenly dispersed food, such as gelada [Dunbar, 1980, 1988] or savanna baboons [Wasser, 1983; Wasser \& Starling, 1986, 1988]. Stress is known to disrupt several aspects of female primate fertility [see review by Abbott, 1987]. Firstly, based on information from human females, stress can interfere with milk production [Seibel \& Taymore, 1982]. Less efficient lactation can in turn give rise to more frequent or prolonged suckling activity [McNeilly et al., 1985]. In both humans and other primates, more frequent nursing results in longer amenorrhea [Lee, 1987], and, when nursing continues after cycling has been resumed, by a longer interval to conception [Nicolson, 1982; Gomendio, 1989]. It is important to note, however, that poor nutrition during lactation can set off the same chain of events. Secondly, stress can disrupt menstrual cycles and ovulation in humans [Seibel \& Taymore, 1982] and other primates [Abbott, 1987], so that conception cannot occur. Rowell $[1970,1972]$ reported that social stress results in longer estrous cycles in captive rhesus and baboon females. Dunbar [1980, 1988] found that the period of peak swelling was lengthened in low-ranking gelada females and attributed this to aggression received from higher-ranking females. Similarly, Wasser \& Starling [1988] reported a significant relationship between the receipt of coalitionary attacks and the number of cycles to conception in wild yellow baboons (although they did not control for the possibility that this relationship was due to a correlation between both variables and low dominance status). Finally, aggression may be linked to pregnancy wastage [Wasser \& Starling, 1988] or perinatal loss, as has been reported by Nash [1974] in a wild baboon female.

The stress hypothesis could potentially help explain the significant lengthening of the duration of cycling in low-ranking females, which was the main cause of their longer interbirth intervals in our study. Support for the stress hypothesis comes from the four females who fell from the top to the bottom of the hierarchy during the study period. They had prolonged interbirth intervals thereafter due to lengthening of both amenorrhea and cycling, in the absence of differences in time spent feeding. No evidence of increased overt harassment was found, but the fallen females did tend to receive more approaches from dominant females, and they were significantly more likely to avoid these approaches than were other low-ranking females. These data do not, of course, prove that more typical levels of stress experienced by females who were low-ranking throughout the study period interfered with reproduction. Low-ranking females did tend to require more cycles to conceive and showed a significantly longer follicular (swelling) phase of the estrous 


\section{2 / Smuts and Nicolson}

cycle, but their entire cycle length was the same as that of high-ranking females. Finally, although Altmann et al. [1988] recently reported a slightly higher incidence of miscarriage in low-ranking yellow baboon females, we were unable to find rank-related differences in pregnancy loss in our small sample.

Maternal style. Altmann et al. [1978] found that high-ranking females were more "laissez faire" in their style of mothering than low-ranking ("restrictive") females and also had shorter periods of postpartum amennorrhea, but this relationship did not hold for total interbirth intervals. In our study troop, maternal rank was not related to measures of nursing frequency or duration [Nicolson, 1982]. Thus, although differences among females in the amount of time spent nursing infants of the same age were clearly reflected in both the length of postpartum amenorrhea and the total interbirth interval in a subsample of the subjects included here [Nicolson, 1982], this source of variance in female fertility appears to be independent of the rank-related patterns reported here. The possibility remains, however, that the same level of nursing could have different effects on reproductive parameters in high- vs. low-ranking females; partitioning our data to answer this question results in sample sizes too small for analysis.

In summary, it is difficult if not impossible to tease apart the relative importance of nutrition vs. stress as mediators of the female dominance-fertility relationship we report; as in most field studies, only indirect and incomplete evidence relevant to the two hypotheses could be obtained. Future studies should ideally incorporate, in addition to data on dominance rank and reproductive parameters, observations of feeding rate, rates and intensity of aggressive interactions, nursing frequency and duration, and repeated determinations of female weight, body fat, and infant growth rates. Even if this information were available, it is unlikely that any one explanation will account for all species, groups, and ecological circumstances.

\section{Dominance Rank and Offspring Sex Ratio}

Based on an analysis of 70 births, maternal rank was not related to the sex ratio of offspring produced. Altmann et al. [1988], in contrast, report skewed offspring sex ratios in the highest-ranking third of the dominance hierarchy (more females produced) and in the lowest-ranking third (more males produced) in yellow baboons. Other studies of cercopithecine primates have found the same, the opposite (i.e., high-ranking females produce more males), or no relationship between maternal rank and offspring sex ratio [reviewed by Small \& Hrdy, 1986]. As discussed by Altmann et al. [1988], the conditions that might favor the production of one sex over the other are as yet poorly understood and can be expected to vary both among species and among populations of the same species. In the case of the Amboseli baboons, an interaction between sex and maternal rank in relation to infant survival, with the highest survivorship among the daughters of highranking and the sons of low-ranking mothers, may be an important selective force [Altmann et al., 1988]. This pattern of infant mortality was not replicated, however, in our data.

\section{Influences of Age and Parity on Reproductive Performance}

In EC troop, interbirth intervals shortened significantly as females aged. Similar results have been reported for other olive baboon troops [Strum \& Western, 1982] and for other primate species [see reviews by Anderson, 1986; Stewart et al., 1988]. However, in many of these other studies, interbirth intervals lengthened again toward the end of the females' reproductive lives, producing an inverted 
U-shaped relationship between age and reproductive performance. Our failure to find a decline in fertility among older females is consistent with results for yellow baboons from Amboseli [Altmann et al., 1988] and vervet monkeys from Amboseli [Cheney et al., 1988] and may be due to small sample sizes in the oldest-age classes. Although one female judged to be old had relatively short birth intervals (Table III), the one very old female in the troop was not included in this analysis because she cycled irregularly and did not conceive or give birth during the 2 years prior to her disappearance.

In our study, two primiparous females whose infants survived had interbirth intervals on average nearly 8 months longer than those of older females, but these differences failed to reach statistical significance. A larger sample of four primiparous females who lost infants prior to the next conception did show significantly longer interbirth intervals than multiparous females who lost infants, due mainly to a significantly longer period of cycling. Several other studies also report a longer period of cycling before the next conception in primiparous females (olive baboons [Scott, 1984]; captive rhesus macaques [Wilson et al., 1983]; Barbary macaques [Paul \& Thommen, 1984]; mountain gorillas [Stewart et al., 1988]); in all but the gorilla case, primiparous females also had significantly longer interbirth intervals. In our study, infant mortality in the first year was significantly higher for offspring of primiparous females, as has been reported in a number of species (yellow baboons [Altmann et al., 1988]; see also Table II in Anderson [1986]). We found no relationship between maternal rank and infant mortality, indicating that the higher fertility of high-ranking females was not offset by higher infant mortality.

\section{CONCLUSIONS}

1. When the previous infant survived until the mother's next conception, birth intervals were significantly shorter for high-vs. low-ranking females, independent of age.

2. The interval from resumption of cycling until conception was significantly shorter for high- vs. low-ranking females.

3. Female rank did not influence infant or adult female mortality, sex ratio at birth, body size, or total estrous cycle length.

4. Interbirth intervals became shorter as females aged.

5. Primiparous females cycled for longer than multiparous females after loss of an infant, and primiparous females experienced higher infant mortality compared with older females.

\section{ACKNOWLEDGMENTS}

We thank the Government of Kenya for permission to conduct research, Jim Else and staff of the Institute for Primate Research, Kenya, for crucial logistical support, Robert Harding and S.C. Strum for permission to study the Gilgil baboons, S.C. Strum for help with female age estimates, and Julie Johnson for use of unpublished demographic data. N.N. received support from an NSF doctoral dissertation improvement award, from an NRSA predoctoral award from NIMH, and from a Grant-in-Aid from Sigma Xi; B.S. received support from the L.S.B. Leakey Foundation and the Wenner-Gren Foundation for Anthropological Research. We thank Chris Crandall, Peter Ellison, Anne McGuire, and John Warner for statistical help. Thanks to David J. Gubernick, Jeanne Altmann, and three anonymous reviewers for valuable comments on a draft of this manuscript. This is publication \#105 of The Evolution and Human Behavior Program, University of Michigan. 


\section{REFERENCES}

Abbott, D.H. Behaviorally mediated suppression of reproduction in female primates. JOURNAL OF ZOOLOGY (LONDON) 213:455-470, 1987.

Altmann, J. BABOON MOTHERS AND INFANTS Cambridge, MA, Harvard University Press, 1980.

Altmann, J.; Altmann, S.A.; Hausfater, G.; McCusky, S. Life history of yellow baboons: Physical development, reproductive parameters, and infant mortality. PRIMATES 18:315-330, 1977.

Altmann, J.; Hausfater, G.; Altmann, S.A. Determinants of reproductive success in savannah baboons (Papio cynocephalus). Pp. 403-418 in REPRODUCTIVE SUCCESS: STUDIES OF INDIVIDUAL VARIATION IN CONTRASTING BREEDING SYSTEMS. T.H. Clutton-Brock, ed. Chicago, University of Chicago Press, 1988.

Altmann, J.; Altmann, S.A.; Hausfater, G. Primate infant's effects on mother's future reproduction. SCIENCE 201:1028-1029, 1978.

Andersen, D.C.; Armitage, K.B.; Hoffman, R.S. Socioecology of marmots: Female reproductive strategies. ECOLOGY 57:552560, 1976.

Anderson, C.M. Female age: Male preference and reproductive success in primates. INTERNATIONAL JOURNAL OF PRIMATOLOGY 7:305-326, 1986.

Berkovitch, F.B. REPRODUCTIVE TACTICS IN ADULT FEMALE AND ADULT MALE OLIVE BABOONS. Ph.D. dissertation, University of California at Los Angeles, 1985.

Berkovitch, F.B. Female weight and reproductive condition in a population of olive baboons (Papio anubis). AMERICAN JOURNAL OF PRIMATOLOGY 12:189195, 1987.

Cheney, D.L.; Seyfarth, R.M.; Andelman, S.J.; Lee, P.C. Reproductive success in vervet monkeys. Pp. 384-402 in REPRODUCTIVE SUCCESS: STUDIES OF INDIVIDUAL VARIATION IN CONTRASTING BREEDING SYSTEMS. T.H. CluttonBrock, ed. Chicago, University of Chicago Press, 1988.

Cox, D.R. Regression models and life tables (with discussion). JOURNAL OF THE ROYAL STATISTICAL SOCIETY (SERIES B) $34: 184-220,1972$.

Datta, S.B. Relative power and the acquisition of rank. Pp. 93-103 in PRIMATE SOCIAL RELATIONSHIPS: AN INTEGRATED APPROACH. R.A. Hinde, ed. Oxford, Blackwell Scientific Publications, 1983.

Dittus, W.P.J. Sex differences in fitness following a group take-over among toque macaques: Testing models of social evolution. BEHAVIORAL ECOLOGY AND SOCIOBIOLOGY 19:257-266, 1986.

Dittus, W.P.J. Population dynamics of the toque monkeys, Macaca sinica. Pp. 125151 in SOCIOECOLOGY AND PSYCHOLOGY OF PRIMATES. R.H. Tuttle, ed. The Hague, Mouton, 1975.

Dixon, W.J.; Brown, M.B.; Engelman, L; Frane, J.W.; Hill, M.A.; Jennrich, R.I.; Toporek, J.D., eds. BMDP STATISTICAL SOFTWARE. Berkeley, University of California Press, 1985.

Drickamer, L.C. A ten-year summary of reproductive data for free-ranging Macaca mulatta. FOLIA PRIMATOLOGICA (BASEL) 21:61-80, 1974.

Dunbar, R.I.M. Determinants and evolutionary consequences of dominance among female gelada baboons. BEHAVIORAL ECOLOGY AND SOCIOBIOLOGY 7:253265, 1980.

Dunbar, R.I.M. PRIMATE SOCIAL SYSTEMS. Ithaca, NY, Cornell University Press, 1988

Fairbanks, L.A.; McGuire, M.T. Determinants of fecundity and reproductive success in captive vervet monkeys. AMERICAN JOURNAL OF PRIMATOLOGY 7:27-38, 1984.

Gomendio, M. Suckling behaviour and fertility in rhesus macaques. JOURNAL OF ZOOLOGY (LONDON) 217:449-467, 1989.

Gouzoules, H.; Gouzoules, S.; Fedigan, L. Behavioral dominance and reproductive success in female Japanese monkeys (Macaca fuscata). ANIMAL BEHAVIOUR 30:11381150,1982 .

Harcourt, A.H. Dominance and fertility among female primates. JOURNAL OF ZOOLOGY (LONDON) 213:471-487, 1987.

Hausfater, G. DOMINANCE AND REPRODUCTIVE SUCCESS IN BABOONS $(P a-$ pio cynocephalus). Basel, Switzerland, S. Karger, 1975.

Hausfater, G.; Altmann, J.; Altmann, S.A. Long-term consistency of dominance relations among female baboons (Papio cynocephalus). SCIENCE 217:752-755, 1982.

Hendrickx, A.G.; Kraemer, D.G. Observations on the menstrual cycle, optimal mating time and pre-implantation embryos of the baboon, Papio anubis and Papio cynocephalus. JOURNAL OF REPRODUCTION AND FERTILITY [SUPPLEMENT] 6:119-128, 1969 .

Hrdy, S.B.; Hrdy, D.B. Hierarchical relations among female hanuman langurs (Primates: Colobinae, Presbytis entellus). SCIENCE 193:913-915, 1976. 
Johnson, J.A. SOCIAL RELATIONSHIPS OF JUVENILE OLIVE BABOONS. Ph.D. Dissertation, University of Edinburgh, 1984.

Johnson, J.A. Dominance rank in juvenile olive baboons, Papio anubis: The influence of gender, size, maternal rank and orphaning. ANIMAL BEHAVIOUR 35:16941708, 1987.

Kaplan, E.L.; Meier, P. Nonparametric estimation from incomplete observations. JOURNAL OF THE AMERICAN STATIS. TICAL ASSOCIATION 53:457-481, 1958.

Kawai, M. On the system of social ranks in Japanese monkeys: Basic rank and dependent rank. Pp. 66-86 in JAPANESE MONKEYS: A COLLECTION OF TRANSLATIONS. K. Imanishi; S.A. Altmann, eds. Chicago, The editors, 1965.

Keverne, E.B.; Eberhart, J.A.; Yodyingyuad, U.; Abbott, D.H. Social influences on sex differences in the behaviour and endocrine state of talapoin monkeys. PROGRESS IN BRAIN RESEARCH 61: 331-341, 1984.

Lee, P.C. Nutrition, fertility and maternal investment in primates. JOURNAL OF ZOOLOGY (LONDON) 213:409-422, 1987.

Loudon, A.S.I.; McNeilly, A.S.; Milne, J.A. Nutrition and lactational control of fertility in red deer. NATURE (LONDON) 302: $145-147,1983$.

Lunn, P.G. Maternal nutrition and lactational infertility: The baby in the driving seat. Pp. 41-53 in MATERNAL NUTRITION AND LACTATIONAL INFERTILI'TY. J. Dobbing, ed. New York, Raven Press, 1985.

McNeilly, A.F.; Glasier, A.; Howie, P.W. Endocrine control of lactational infertility. Pp. $1-24$ in MATERNAL NUTRITION AND LACTATIONAL INFERTILITY. J. Dobbing, ed. New York, Raven Press, 1985.

Mori, A. Analysis of population changes by measurement of body weight in the Koshima troop of Japanese monkeys. PRIMATES 20:371-397, 1979.

Nash, L. Parturition in a feral baboon (Papio anubis). PRIMATES 15:279-285, 1974.

Nicolson, N. WEANING AND THE DEVELOPMENT OF INDEPENDENCE IN OLIVE BABOONS. Ph.D. Dissertation, Harvard University, 1982.

Paul, A.; Thommen, D. Timing of birth, female reproductive success and infant sex ratio in semi-freeranging Barbary macaques (Macaca sylvanus). FOLIA PRIMATOLOGICA (BASEL) 42:2-16, 1984.

Post, D.G. Activity patterns of yellow baboons (Papio cynocephalus) in the Amboseli National Park, Kenya. ANIMAL BEHAVIOUR 29:357-374, 1981.
Post, D.G.; Hausfater, G.; McCuskey, S.A. Feeding behavior of yellow baboons (Papio cynocephalus): Relationship to age, gender, and dominance rank. FOLIA PRIMATOLOGICA (BASEL) 34:170-195, 1980.

Rasmussen, K.L.R. Changes in the activity budgets of yellow baboons (Papio cynocephalus) during sexual consortships. BEHAVIORAL ECOLOGY AND SOCIOBIOLOGY 17:161-170, 1985.

Rowell, T.E. Baboon menstrual cycles affected by social environment. JOURNAL OF REPRODUCTION AND FERTILITY 21:133-141, 1970.

Rowell, T.E. SOCIAL BEHAVIOUR OF MONKEYS. Harmondsworth, England, Penguin, 1972.

Sade, D.S. Determinants of dominance in a group of free-ranging rhesus monkeys. Pp. 99-114 in SOCIAL COMMUNICATION AMONG PRIMATES. S.A. Altmann, ed. Chicago, University of Chicago Press, 1967.

Sadleier, R.M.S. THE ECOLOGY OF REPRODUCTION IN WILD AND DOMESTIC MAMMALS. London, Methuen, 1969.

Scott, L.M. Reproductive behavior of adolescent female baboons (Papio anubis) in Kenya. Pp. 77-102 in FEMALE PRIMATES: STUDIES BY WOMEN PRIMATOLOGISTS. M.F. Small, ed. New York, Alan R. Liss, Inc., 1984.

Seibel, M.M.; Taymor, M.L. Emotional aspects of infertility. FERTILITY AND STERILITY 37:137-145, 1982.

Seyfarth, R.M. The distribution of grooming and related behaviours among adult female vervet monkeys. ANIMAL BEHAVIOUR 28:798-813, 1980.

Shaikh, A.; Celaya, C.; Gomez, I.; Shaikh, S. Temporal relationship of hormonal peaks to ovulation and sex skin deturgescence in the baboon. PRIMATES 22:444-452, 1982.

Silk, J.B. Eating for two: Behavioral and environmental correlates of gestation length among free-ranging baboons (Papio cynocephalus). INTERNATIONAL JOURNAL OF PRIMATOLOGY 7:583-602, 1986.

Silk, J.B. Social behavior in evolutionary perspective. Pp. 318-329 in PRIMATE SOCIETIES. B.B. Smuts; D.L. Cheney; R.M. Seyfarth; R.W. Wrangham; T. Struhsaker, eds. Chicago, University of Chicago Press, 1987.

Silk, J.B. Social mechanisms of population regulation in a captive group of bonnet macaques (Macaca radiata). AMERICAN JOURNAL OF PRIMATOLOGY 14: 111-124, 1988

Silk, J.B.; Clark-Wheatley, C.; Rodman, P.S.; Samuels, A. Differential reproductive success and facultative adjustment of sex ratios among captive female bonnet 
macaques (Macaca radiata). ANIMAL BEHAVIOUR 29:1106-1120, 1981a.

Silk, J.B.; Samuels, A.; Rodman, P.S. Hierarchical organization of female Macaca ra diata. PRIMATES 22:84-85, $1981 \mathrm{~b}$.

Simpson, M.J.; Simpson, A.; Hooley, J.; Zunz, M. Infant-related influences on birth intervals in rhesus monkeys. NATURE (LONDON) 290:49-51, 1981.

Simpson, M.J.; Simpson, A. Short-term consequences of different breeding histories for captive rhesus macaque mothers and young. BEHAVIORAL ECOLOGY AND SOCIOBIOLOGY 18:83-89, 1985.

Small, M.F.; Hrdy, S.B. Secondary sex ratios by maternal rank, parity, and age in captive rhesus macaques (Macaca mulatta). AMERICAN JOURNAL OF PRIMATOLOGY 11:359-365, 1986.

Smuts, B.B. SEX AND FRIENDSHIP IN BABOONS. Hawthorne, New York, Aldine, 1985.

Strum, S.C.; Western, D. Variations in fecundity with age and environment in olive baboons (Papio anubis). AMERICAN JOURNAL OF PRIMATOLOGY 3:61-76, 1982.

Stewart, K.J.; Harcourt, A.H.; Watts, D.P. Determinants of fertility in wild gorillas and other primates. Pp. 22-38 in NATURAL HUMAN FERTILITY: SOCIAL AND BIOLOGICAL MECHANISMS. P. Diggory; M. Potts, eds. London, Macmillan, 1988.

Sugiyama, Y.; Ohsawa, H. Population dynamics of Japanese monkeys with special reference to the effect of artificial feeding. FOLIA PRIMATOLOGICA (BASEL) 39: 238-263, 1982.

van Schaik, C.P. Why are diurnal primates living in groups? BEHAVIOUR 87: 120-144, 1983.

van Schaik, C.P.; van Noordwijk, M.A. Evolutionary effect of the absence of felids on the social organization of the Simeulue monkey (Macaca fascicularis fusca, Mil- ler 1903). FOLIA PRIMATOLOGICA (BASEL) 44:138-147, 1985.

Walters, J. Interventions and the development of dominance relationships in female baboons. FOLIA PRIMATOLOGICA (BASEL) 34:61-89, 1980.

Wasser, S.K. Reproductive competition and cooperation among female yellow baboons. Pp. 349-390 in SOCIAL BEHAVIOUR OF FEMALE VERTEBRATES. S.K. Wasser, ed. NY: Academic Press, 1983.

Wasser, S.K.; Starling, A.K. Reproductive competition among female yellow baboons. Pp. 343-354 in PRIMATE ONTOGENY, COGNITION, AND BEHAVIOUR. J.G. Else; P.C. Lee, eds. Cambridge, Cambridge University Press, 1986

Wasser, S.K.; Starling, A.K. Proximate and ultimate causes of reproductive suppression among female yellow baboons at $\mathrm{Mi}$ kumi National Park, Tanzania. AMERICAN JOURNAL OF PRIMATOLOGY 16: 97-121, 1988.

Whitten, P.L. Diet and dominance among female vervet monkeys (Cercopithecus aethiops). AMERICAN JOURNAL OF PRIMATOLOGY 5:139-159, 1983.

Wildt, D.E.; Doyle, L.L.; Stone, S.C.; Harrison, R.M. Correlation of perineal swelling with serum ovarian hormone levels, vaginal cytology, and ovarian follicular development during the baboon reproductive cycle. PRIMATES 18:261-270, 1977.

Wilson, M.E; Gordon, T.P.; Bernstein, I.S. Timing of births and reproductive success in rhesus monkey social groups. JOURNAL OF MEDICAL PRIMATOLOGY 7: 202-212, 1978.

Wilson, M.E.; Walker, M.L.; Gordon, T.P. Consequences of first pregnancy in rhesus monkeys, AMERICAN JOURNAL OF PHYSICAL ANTHROPOLOGY 61: $103-110,1983$.

Wrangham, R.W. Drinking competition in vervet monkeys. ANIMAL BEHAVIOUR 29:904-910, 1981. 